\title{
Suppressed response to hormonal contraceptives in women of Khairpur, Sindh, Pakistan ${ }^{*}$
}

\author{
Yasmeen Faiz Kazi ${ }^{1 \#}$, Sobia Saleem ${ }^{1}$, Nasreen Kazi ${ }^{2}$ \\ ${ }^{1}$ Department of Microbiology, Shah Abdul Latif University, Khairpur, Pakistan; \\ ${ }^{\#}$ Corresponding Author: yameen.kazi@salu.edu.pk, yfkazi@yahoo.com \\ ${ }^{2}$ Department of Pharmacology, Liaqat University of Medical and Health Sciences, Jamshoro, Pakistan
}

Received 27 August 2013; revised 28 September 2013; accepted 8 October 2013

Copyright (C) 2013 Yasmeen Faiz Kazi et al. This is an open access article distributed under the Creative Commons Attribution License, which permits unrestricted use, distribution, and reproduction in any medium, provided the original work is properly cited.

\begin{abstract}
Objective: Contraception has gained gradual popularity in many parts of the developing world including Pakistan. Despite this increase in acceptance, the birth rate remains high. Failure of contraception has been reported in the literature, which made us aim to conduct this study. The efficiency of hormonal contraceptives in the study area was assessed and this is the first report from Pakistan. Methods: A total of 200 women (aged $20-30$ and $31-40$ years; $n=100$ each) with minimum consistent use of hormonal contraceptives in the form of pills (Combined oral contraceptives) for 12 months were enrolled in this study. Blood samples were collected from women of each age group and corresponding control groups $(n=100)$ from local hospitals and reproductive health service center. Serum levels of the fertility hormones viz leutinizing and follicle stimulating hormones were measured through ELISA technique. Results: Our data revealed that over all in the both age groups, $72 \%$ women had normal, $16 \%$ increased and $12 \%$ showed decreased levels of leutinizing hormone $(p>0.05)$ and $67 \%$ women showed normal, $33 \%$ showed decreased and no increased levels were found for follicle stimulating hormone $(p>0.05)$. No age-wise significant difference in response was observed among both the age groups tested. Conclusion: Statistically insignificant difference in serum leutinizing hormone and follicle stimulating hormone seen among both the age groups of hormonal contraceptive users and control group indicates less effective hormonal contraception response in the study area.
\end{abstract}

\footnotetext{
"Conflict of interest: The authors declare no conflict of interests.
}

Keywords: Contraceptive; Women; Response

\section{INTRODUCTION}

Worldwide more than 100 million women choose hormonal contraception for family planning [1]. The mode of action of Estrogen- and progesterone-containing oral hormonal contraceptives (HC) is suppression of ovulation, suppression of mid cycle peaks of leutinizing hormone (LH) and follicle stimulating hormone (FSH) [2]. Combined pills suppress FSH and LH throughout the cycle $[3,4]$. In spite of the general usage of significantly effective contraceptive, it is reported that $49 \%$ of pregnancies occurred unintentionally in the USA [5]. Around half of the unintended pregnancies have been reported due to contraceptive failure [6]. Another study in France also documents pregnancies in presence of consistent use of contraception where $82 \%$ of contraceptive users were using the pill or the intrauterine device (IUD) where $1 / 3$ pregnancies were unintended, and the pregnancies occurred in $65 \%$ women at the time when they were on contraceptives [7].

In Khairpur, a sub-urban city of Sindh, Pakistan, the total women population, according to the census of 1998 is 0.736 million and growth rate is $2.71 \%$, with 5.3 per women fertility rate [8]. We presume that the high population rate may be due to ineffective contraception. Hence in the present study, the usage and response of oral contraceptives in the women of Khairpur were evaluated.

\section{METHODS}

The data of women using $\mathrm{HC}$ were taken from the different hospitals of Khairpur city. The hospitals include Civil Hospital, Lady Wellington Hospital, Reproductive Health Services and Maternity Home Luqman. The District Health Committee, Khairpur approved this study.

The data of women from age groups (20 - 30 and 31 - 
40 years) was obtained. A total of 100 women per group with minimum consistent use of $\mathrm{HC}$ in the form of COCs pills (Combined oral contraceptives) for 12 months were enrolled in this study. Blood samples $(n=100$ for each group) were randomly collected from different hospitals and checked for two fertility hormones viz LH and FSH. An informed verbal consent was acquired from the women who participated in this study.

A volume of $5 \mathrm{cc}$ of the blood samples were drawn using sterile disposable syringes by simple vein puncture method. The serum was separated after one hour of blood collection by centrifugation at $6000 \mathrm{rpm}$ for 5 minutes at room temperature for taking away of residual RBCs. Serum was kept frozen at $-20^{\circ} \mathrm{C}$ for further studies. Later the investigation of the serum levels (normal, increased and decreased $\mathrm{mIU} / \mathrm{ml}$ ) of $\mathrm{LH}$ and $\mathrm{FSH}$ were carried out in the Diagnostic and Research Center, Department of Microbiology Shah Abdul Latif University Khairpur using enzyme linked immunosorbant assay (ELISA) kit (Active LH/FSH ELISA. DSL-10-4600, Diagnostic System Laboratories, Inc. USA) according to the manufacturer's instructions.

\section{Statistical Analysis}

The mean absorbance for each standard, control and test samples of HC users was calculated using a linearlinear or semi log graph, plotted the mean absorbance readings for each of the standard along with y-axis and the $\mathrm{x}$-axis and the duplicate points. The LH and FSH of standard controls and test serum of hormonal contraceptive was calculated from the standard curve by matching their mean absorbance reading with the corresponding $\mathrm{LH}$ and FSH concentrations. The units were formulated through the statistical soft ware, (SPSS 10.0) using the log normal probability plot because these were extreme values of users of hormonal contraceptives. One sample $t$ test was used to calculate $p$ values for $\mathrm{LH}$ and FSH. Unpaired Two-tailed t test was used to calculate $p$ values for statistical significance between $\mathrm{HC}$ users and control groups (Appendix).

\section{RESULTS}

During the survey of one year, total users of $\mathrm{HC}$ from the age group 20 - 30 years, were 3898 and in the age group 31 - 40 years, the number was 7983 (approximately twice). It was further observed that the oral pill was the most popular method of contraception followed by injectible and norplant (data not shown).

The normal range of $\mathrm{LH}$ is 1.00 to $11.44 \mathrm{mIU} / \mathrm{ml}$. In our results, overall in both age groups (20 - 30 and 31 40 years), 72\% women showed normal, 16\% showed increased and $12 \%$ women showed decreased levels of LH.

Age group wise; $76 \%$ of the women of 20 - 30 years showed normal, $18 \%$ showed increased and $6 \%$ showed decreased levels of $\mathrm{LH}$ where in the women of age group 31 - 40 years, 68\% showed normal, 14\% showed increased and $18 \%$ showed decreased levels of LH.

The normal range of FSH is 1.50 to $8.21 \mathrm{mIU} / \mathrm{ml}$. In our results, overall in both groups $67 \%$ women showed normal, $33 \%$ women showed decreased and no increased levels for FSH were observed.

Age group wise; $69 \%$ women of 20 - 30 years showed normal and $31 \%$ showed decreased levels of FSH where in the women of age group 31 - 40 years, $65 \%$ showed normal and $35 \%$ showed decreased levels of FSH. The data are summarized in Table $\mathbf{1 .}$

Statistical analysis trend showed that the data was normal and variables were closely related (Figures 1-4).

Table 1. Determination of LH and FSH concentrations in the users of hormonal contraceptives in women of different age groups.

\begin{tabular}{ccccccccc}
\hline & & \multicolumn{6}{c}{ Type of hormone } \\
\cline { 3 - 8 } Catagory & Age group (years) & LH (mIU/ml) & FSH (mIU/ml) \\
\cline { 3 - 8 } & & N & I & D & N & I & D \\
\hline Test (over all) & Both age groups & 72 & 16 & 12 & 67 & 0 & 33 \\
Test (age-wise) & $20-30$ & 76 & 18 & 6 & 69 & 0 & 31 \\
& $31-40$ & 68 & 14 & 18 & 65 & 0 & 35 \\
Control & $20-30$ & 68 & 10 & 22 & 61 & 0 & 39 \\
& $31-40$ & 59 & 8 & 33 & 62 & 0 & 38 \\
\hline
\end{tabular}

Note: $\mathrm{N}=$ Normal, $\mathrm{I}=$ Increased, $\mathrm{D}=$ Decreased Blood samples from the women using hormonal contraceptives were collected and investigated for serum LH and FSH levels as described in materials and methods. The table shows the trend (\%) of increased, decreased and normal concentration of LH and FSH.

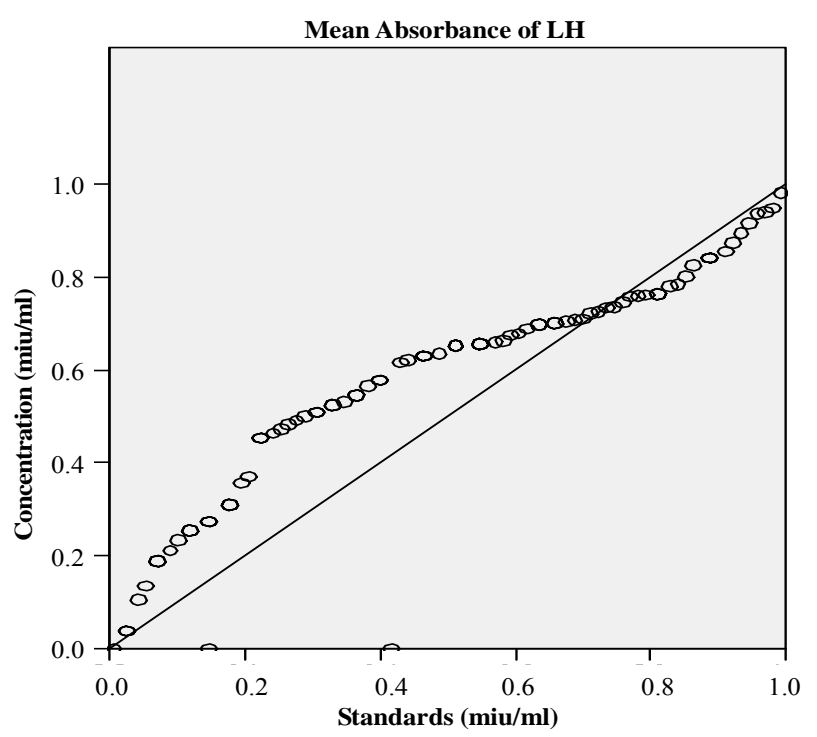

Figure 1. Mean absorbance of leutinizing hormone present in sera of women using hormonal contraceptives in Khairpur. 


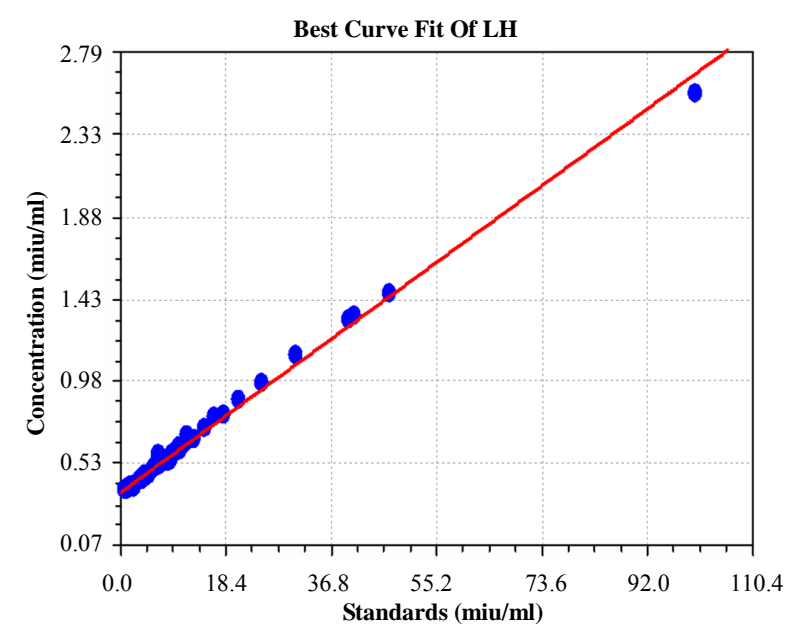

Figure 2. Best curve fit for leutinizing hormone present in sera of women using hormonal contraceptives in Khairpur.

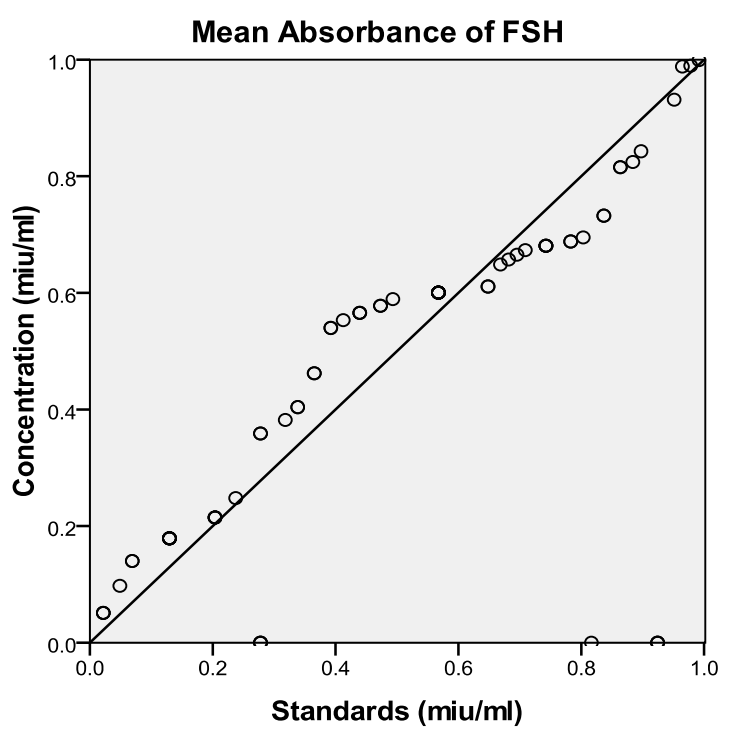

Figure 3. Mean absorbance of follicle stimulating hormone present in sera of women using hormonal contraceptives in Khairpur.

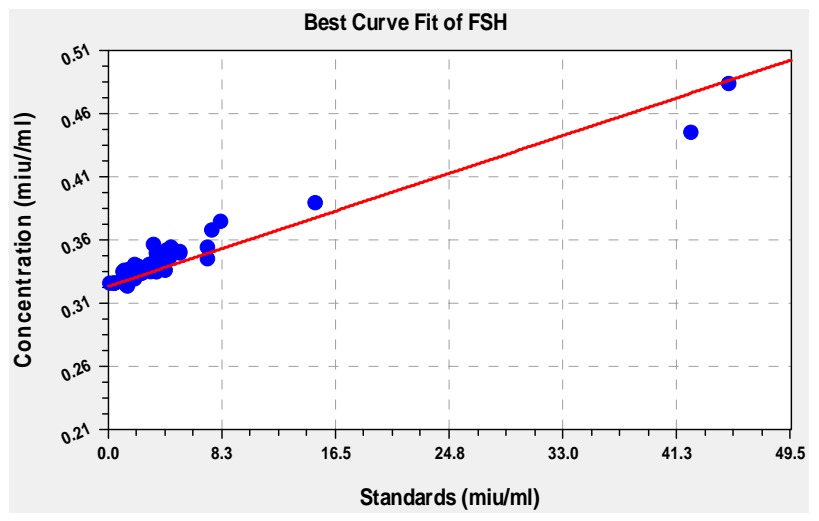

Figure 4. Best curve fit for follicle stimulating hormone present in sera of women using hormonal contraceptives in Khairpur.

\section{DISCUSSION}

This study presents data about the use of hormonal contraceptives among women of different age groups (20 - 30 and 31 - 40 years) and the corresponding levels of fertility hormones viz LH and FSH.

Pakistan being among the first countries in South Asia to launch a national family planning program in 1960 , has gradually improved its performance in contraceptive usage. However, acceptability of contraception is low among rural women in Pakistan [9].

Our findings indicate that over all, a fraction of total female population was using hormonal contraceptives in Khairpur. When compared, pills (COCs) were found to be the more acceptable contraception method in the women of both age groups. Our findings showed statistically insignificant difference in the serum levels of the fertility hormones ( $\mathrm{LH}$ and $\mathrm{FSH}$ ) when compared with the control groups. Test of homogeneity and equality of variances were also approximated to check the variation. Significant $\mathrm{p}$-values less than 0.05 showed that the variances were approximately equal and samples were not biased. No statistically important difference in overall or utmost concentrations of LH, and FSH were observed in contraceptive users of both age groups and the control groups. The two-tailed p-values showed insignificant difference between both age groups, indicating that the age of women had no or negligible relation to the response towards HC. These results convey that using hormonal contraceptives did not alter the fertility hormones LH and FSH in HC users and therefore had insignificant effect which is not in agreement with the published literature [10-13] and demonstrating the ineffectiveness of the contraceptives in the test population.

Recent data shows that population growth rate in Pakistan is high with total fertility rate of 3.6 and estimated population of 177 million in 2011 that is growing at a rate of $2.05 \%$ annually [9] It emphasizes the need for efficient family planning surveillance in Pakistan. Our data revealed that the use of hormonal contraceptive was not efficient as far as the serum levels of LH and FSH were concerned. The failure could be on account of the other reasons such as drug to drug interaction or as a result of increased body mass index in the users therefore, altering pharmacokinetics by altering the absorption, distribution, metabolism or excretion of $\mathrm{HC}$ and/or affecting pharmacodynamics by affecting clinical actions of hormonal contraceptives as a result of synergy or antagonism $[14,15]$. In a recent study, adverse role of antibiotics in efficiency of combined oral contraceptives has been suspected [16]. Interaction between oral contraceptives and anti-epileptic drugs has also been reported, in which the ineffective response towards oral contraceptives has been established [17]. As drug-drug interaction was not the scope of our study, we could only presume 
and not ascertain that the insignificant response to $\mathrm{HC}$ was actually due to the interaction of any drug.

Conclusively, suppressed response to $\mathrm{HC}$ assessed by insignificant alteration of LH and FSH serum levels in the $\mathrm{HC}$ users of both age groups indicate a sub-optimal efficiency of this method of contraception in Khairpur and further studies on the possible reason(s) for this decreasing $\mathrm{HC}$ response may be elucidated.

\section{KEY MASSAGE}

- Hormonal contraception appeared as the most preferred method in Khairpur.

- Despite contraception usage, fertility rate appeared to be high.

- Insignificant response to hormonal contraception was observed in both age groups.

- Hormonal contraception usage may be monitored in correlation of response.

\section{ACKNOWLEDGEMENTS}

We are thankful to Directorate of Research Shah Abdul Latif University for funding this project and Mr. Amjad Ali Mughal for technical assistance in ELISA.

\section{REFERENCES}

[1] Huezo, C.M. (1998) Current reversible contraceptive methods: A global perspective. International Journal of Gynecology \& Obstetrics, 62, S3-S15. http://dx.doi.org/10.1016/S0020-7292(98)00084-8

[2] Vazque, H.L., Tellez, M.J. and Hiks, G.J. (2000) Clinical and metabolic effects of oral contraceptives. Obstetrics \& Gynecology, 68, 64-69.

[3] Jung-Hoffman, C., Heidt, F. and Kuhl, H. (1988) Effect of two oral contraceptives containing $30 \mu \mathrm{g}$ ethinyestradiol and $75 \mu \mathrm{g}$ gestodene or $150 \mu \mathrm{g}$ desogestrel upon various parameters. Contraception, 38, 593-603. http://dx.doi.org/10.1016/0010-7824(88)90044-3

[4] Hatcher, R.A. and Guillebaud, M.A. (1998) The pill: combined oral contraceptives. In: Hatcher, R.A., Trussell, J., Stewart, F., et al., Eds., Contraceptive Technology, Ardent Media, New York, 405-466.

[5] Finer, L.B. and Henshaw, S.K. (2006) Disparities in rates of unintended pregnancy in the United States, 1994 and 2001. Perspectives on Sexual and Reproductive Health, 38, 90-96. http://dx.doi.org/10.1363/3809006
[6] Mosher, W.D., Martinez, G.M., Chandra, A., Abma, J.C., Wilson, S.J., Hyattsville, M.D., National Center for Health Statistics (2004) Use of contraception and use of family planning services in the United States: 1982-2002. Advance Data from Vital and Health Statistics, 350.

[7] Bajos, N., Leridon, H. and Job Spira, N. (2004) Contraception and abortion in France in the 2000s. The COCON survey. Population, 3-4, 347-356. http://dx.doi.org/10.3917/pope.403.0347

[8] Population reference bureau 2011 world population data sheet. www.prb.org

[9] Population welfare department government of Sindh 2011. http://www.pwdsindh.gov.pk/khairpur

[10] Robinstein, L., Moguilevsky, F.M. and Leiderman, S. (1978) The effect of oral contraceptives on the gonadotropin response to LHRH. Obstetrics \& Gynecology, 52, 571-574.

[11] Goldzier, J.W., Kleber, J.W., Moses, L.E. and Rathmacher, R.P. (1970) A cross-sectional study of plasma FSH and LH levels in women using sequential, combination or injectable steroid contraceptives over long periods of time. Contraception, 2, 225-248. http://dx.doi.org/10.1016/0010-7824(70)90035-1

[12] Slaats, E.H., Kennedy, J.C., de Vries, R.K. and Schoemaker, J. (1993) Pulsatile leutinizing hormone patterns in long term oral contraceptives users. The Journal of Clinical Endocrinology \& Metabolism, 77, 2420-2426.

[13] Tafurt, C.A., Sobrevilla, L.A. and De Estrada, R. (1980) Effects of progestin-estrogen combination and progestational contraceptives on pituitary gonadotropins, gonadal steroids and sex hormone-binding globulin. Fertility and Sterility, 33, 261-266.

[14] Holt, V.L., Scholes, D., Wicklund, K.G., Cushing-Haugen, K.L. and Daling, J.R. (2005) Body mass index, weight, and oral contraceptive failure risk. Obstetrics \& Gynecology, 105, 46-52. http://dx.doi.org/10.1097/01.AOG.0000149155.11912.52

[15] (2012) Faculty of sexual and reproductive healthcare drug interactions with hormonal contraceptive. Registered in England No. 2804213 and Charity No. 1019969.

[16] Toh, S., Mitchell, A.A., Anderka, M., de Jong-van den Berg, L.T. and Hernández-Díaz, S. (2011) Antibiotics and oral contraceptive failure-A case-crossover study. Contraception, 83, 418-425. http://dx.doi.org/10.1016/j.contraception.2010.08.020

[17] Wang, H., Bos, J.H. and de Jong-van den Berg, L.T. (2012) Co-prescription of antiepileptic drugs and contraceptives. Contraception, 85, 28-31. http://dx.doi.org/10.1016/j.contraception.2011.04.017 


\section{APPENDIX}

Unpaired $t$ test results

Statistical analysis of LH (Test VS Control groups)

$P$ value and statistical significance:

The two-tailed P value equals 0.9082 .

By conventional criteria; this difference is considered to be not statistically significant.

Confidence interval:

The mean of Group One minus Group Two equals 3.33 .

95\% confidence interval of this difference: From -72.01 to 78.68 .

Intermediate values used in calculations:

$\mathrm{t}=0.1228$;

$\mathrm{df}=4$;

standard error of difference $=27.138$.

Review of data:

\begin{tabular}{ccc}
\hline Group & Group One & Group Two \\
\hline Mean & 33.33 & 30.00 \\
SD & 33.55 & 32.92 \\
SEM & 19.37 & 19.01 \\
$\mathrm{~N}$ & 3 & 3 \\
\hline
\end{tabular}

Unpaired $t$ test results

Statistical analysis of FSH (Test vs Control groups)

$P$ value and statistical significance:

The two-tailed $P$ value equals 0.7938 .

By conventional criteria; this difference is considered to be not statistically significant.

\section{Confidence interval:}

The mean of Group One minus Group Two equals 8.83 .

95\% confidence interval of this difference: From -89.62 to 107.28 .

Intermediate values used in calculations:

$\mathrm{t}=0.2855$

$\mathrm{df}=3$;

standard error of difference $=30.935$.

Review of data:

\begin{tabular}{ccc}
\hline Group & Group One & Group Two \\
\hline Mean & 33.33 & 24.50 \\
SD & 33.50 & 34.65 \\
SEM & 19.34 & 24.50 \\
N & 3 & 2 \\
\hline
\end{tabular}

One sample $t$ test results

$P$ value and statistical significance:

The two-tailed $P$ value equals 0.0010 .

By conventional criteria; this difference is considered to be very statistically significant.

\section{Confidence interval:}

The hypothetical mean is 0.00 .

The actual mean is 72.00 .

The difference between these two values is 72.00 .

The $95 \%$ confidence interval of this difference:

From 62.06 to 81.94 .

Intermediate values used in calculations:

$\mathrm{t}=31.1769$;

$\mathrm{df}=2$;

standard error of difference $=2.309$.

Sera of women (20 - 30 and 31 - 40 years) using HC were collected and processed for estimation of $\mathrm{LH}$ and FSH using ELISA. The Figures show the best mean absorbance and curve fit of the samples tested. This work is licensed under a Creative Commons Attribution-NonCommercial-NoDerivs 3.0 Unported License. 